\title{
Ionic Liquid-Based Optical and Electrochemical Carbon Dioxide Sensors
}

\author{
Kamalakanta Behera ${ }^{1}$, Shubha Pandey ${ }^{2}$, Anu Kadyan ${ }^{1}$ and Siddharth Pandey ${ }^{1, *}$ \\ Received: 27 August 2015; Accepted: 1 December 2015; Published: 4 December 2015 \\ Academic Editors: Xiangqun Zeng, Michael T. Carter and Abdul Rehman \\ 1 Department of Chemistry, Indian Institute of Technology Delhi, Hauz Khas, New Delhi 110016, India; \\ kamala.iitd@gmail.com (K.B.); anu.kadyan1@gmail.com (A.K.) \\ 2 Department of Science and Technology, Ministry of Science and Technology, Technology Bhawan, \\ New Mehrauli Road, New Delhi 110016, India; shubha.p@nic.in \\ * Correspondence: sipandey@chemistry.iitd.ac.in; Tel.: +91-11-2659-6503; Fax: +91-11-2658-1102
}

\begin{abstract}
Due to their unusual physicochemical properties (e.g., high thermal stability, low volatility, high intrinsic conductivity, wide electrochemical windows and good solvating ability), ionic liquids have shown immense application potential in many research areas. Applications of ionic liquid in developing various sensors, especially for the sensing of biomolecules, such as nucleic acids, proteins and enzymes, gas sensing and sensing of various important ions, among other chemosensing platforms, are currently being explored by researchers worldwide. The use of ionic liquids for the detection of carbon dioxide $\left(\mathrm{CO}_{2}\right)$ gas is currently a major topic of research due to the associated importance of this gas with daily human life. This review focuses on the application of ionic liquids in optical and electrochemical $\mathrm{CO}_{2}$ sensors. The design, mechanism, sensitivity and detection limit of each type of sensor are highlighted in this review.
\end{abstract}

Keywords: ionic liquids; carbon dioxide; sensors; optical sensors; electrochemical sensors

\section{Introduction}

Ionic liquids belong to an exciting class of solvents and have received increased attention from both academic and industrial research communities all over the world as a replacement for conventional solvents in a wide range of applications [1-5]. Ionic liquids are defined as salts with their ions weakly coordinated and remain in the liquid state at temperatures below $100{ }^{\circ} \mathrm{C}$. They are typically comprised of a bulky organic cation (e.g., alkyl-substituted ammonium, imidazolium, pyrrolidinium, etc.) paired with an inorganic or organic anion (e.g., halide ions, tetrafluoroborate, hexafluorophosphate, acetate, etc.) (Figure 1). Ionic liquids possess several archetypal properties, such as low volatility, high thermal and chemical stability, good electrical conductivity, wide electrochemical windows, wide liquid range, high polarity and good ability to dissolve a wide range of compounds [6-10]. Their negligible vapor pressure and non-flammability have contributed to their common epithet as "green solvents", and as a result, they have been viewed as alternative replacements for the hazardous and volatile organic solvents largely used in diverse research areas. Ionic liquids are often termed as designer solvents, as their physicochemical properties can be tuned just by tuning the structure of the cation and/or anion [6-10]. Thus, one can synthesize an ionic liquid for a specific application simply by manipulating its key physicochemical properties as a result of the appropriate selection of cation and anion combinations. This key feature, along with their dual behavior as electrolyte and solvent, make them an exciting candidate to be used in diverse research areas of science and technology. These environmentally-benign designer solvents find immense applications in various fields, namely in wide range of synthetic, catalytic and biochemical reactions, separation and extraction processes, as energetic materials, in pharmaceutics, biotechnology, as 
lubricants, heat transfer fluids, in biocatalysis, nanoscience, among many others [11-18]. Ionic liquids have also become recognized as ideal alternative electrolytes for use in many electrochemical devices, such as batteries, capacitors, fuel cells and solar cells [19-22]. In addition to the above applications, ionic liquids are vastly used in the sensing of biomolecules (e.g., nucleic acids, proteins and enzymes), various relevant gases (e.g., $\mathrm{O}_{2}, \mathrm{CO}_{2}, \mathrm{CO}, \mathrm{SO}_{2}, \mathrm{H}_{2} \mathrm{~S}, \mathrm{NO}_{2}, \mathrm{Cl}_{2}$ ), several ions of importance and sensing of explosives and chemical warfare agents (CWAs) [23-32].
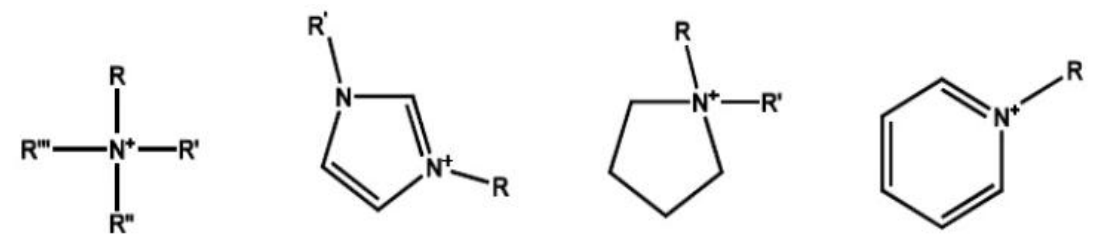
Tetraalkylammonium N,N'-dialkylimidazolium N,N-dialkylpyrrolidinium N-alkylpyrridinium $\left(\left[\mathrm{N}_{\mathrm{a}, \mathrm{b}, \mathrm{c}, \mathrm{d}}\right]^{+}\right)$ $\left(\left[\mathrm{C}_{\mathrm{n}} \mathrm{mim}\right]^{+}\right)$ $\left(\left[\mathrm{Py} \mathrm{y}_{\mathrm{ab}}\right]^{+}\right)$ $\left(\left[\mathrm{C}_{\mathrm{n}} \mathrm{mpyrr}\right]^{+}\right)$

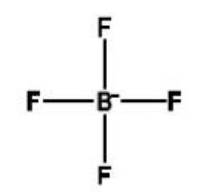

Tetrafluoroborate Hexafluorophosphate $\left(\left[\mathrm{BF}_{4}\right]^{-}\right)$

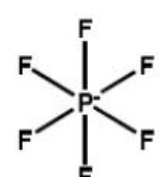

$\left(\left[\mathrm{PF}_{6}\right]^{-}\right)$

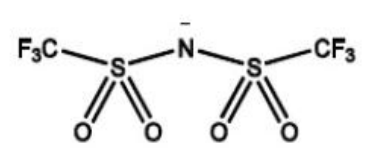

Bis(trifluoromethylsulfo- Trifluoromethanesulf onate nyl)imide $\left(\left[\mathrm{Tf}_{2} \mathrm{~N}\right]^{-}\right)$

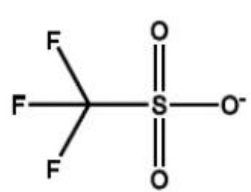

([OTf] $\left.]^{-}\right)$

Figure 1. Structures of cations and anions of some commonly-used ionic liquids.

One of the major problems receiving increased attention is the high levels of carbon dioxide $\left(\mathrm{CO}_{2}\right)$, which have been implicated in climate change and have threatened not only numerous economies, but also the environment of the planet. $\mathrm{CO}_{2}$ gas generally produced by fossil fuel combustion and by living beings is a greenhouse gas responsible for global warming. $\mathrm{CO}_{2}$ is dangerous to human lives when present at high concentrations. The U.S. Occupational Safety and Health Administration consider a $\mathrm{CO}_{2}$ concentration above $4 \%$ as "dangerous to life and health". In addition to environmental monitoring, a variety of other applications exist where knowing the $\mathrm{CO}_{2}$ concentration is essential. The continuous and accurate monitoring of $\mathrm{CO}_{2}$ levels is of vital importance in environmental monitoring, respiratory analysis, sea water analysis, medicine and biological processes [33-36]. The development of a sensor with high sensitivity and selectivity that is capable of detecting $\mathrm{CO}_{2}$ and quantifying its concentration in a reliable and inexpensive manner is of significant importance to both the medical profession and socially-responsible industries [37,38].

The intrinsic properties of ionic liquids mentioned earlier suggest that these can be potentially used as an advantageous media for the development of stable and robust $\mathrm{CO}_{2}$ gas sensors. Ionic liquids possess high thermal stability and low volatility, meaning that they have the ability to sustain high temperatures and pressures, thus enabling them to perform under conditions where conventional organic solvents would struggle to remain physically and chemically unchanged, and as such, can be used where organic solvents would fail [1-10]. They exhibit wide electrochemical windows, which allow for the investigation of compounds that may have been inaccessible otherwise [39-42]. Further, their dual behavior as electrolyte and solvent makes them an exciting candidate for sensing purposes [23-32]. One of the added benefits of using these designer solvents is that they offer many options for chemical modifications, allowing greater flexibility in designing molecular recognition sites in their structures. These possibilities offer opportunities to explore the applications of ionic liquids in the highly sensitive and selective determination of trace amounts of $\mathrm{CO}_{2}$ gas using them in sensor arrays [28-30]. For example, a task-specific ionic liquid with an amine $\left(-\mathrm{NH}_{2}\right)$ group on the cation can capture $\mathrm{CO}_{2}$ and significantly enhance the solubility of $\mathrm{CO}_{2}$ in that 
particular ionic liquid [43]. A wide range of ionic liquid-based sensors has been developed so far for the detection and quantification of $\mathrm{CO}_{2}$ gas [44-70]. These ionic liquid-based $\mathrm{CO}_{2}$ sensors are either optical-based [44-57] or electrochemical-based sensors [58-70].

Optical $\mathrm{CO}_{2}$ sensors based on the changes in the absorbance or fluorescence response have been reported by researchers [44-57]. Usually, these optical sensors contain a chemically-active sensing agent, which changes the UV-VIS absorbance or fluorescence emission intensity in response to $\mathrm{CO}_{2}$. Oter et al. used ionic liquids 1-methyl-3-butylimidazolium tetrafluoroborate and 1-methyl-3-butylimidazolium bromide in optical $\mathrm{CO}_{2}$ sensing together with an ion pair form of acid base indicator, bromothymol blue [44-48]. Water-miscible ionic liquids were exploited as an optical sensor matrix material for sensing of both gaseous and dissolved $\mathrm{CO}_{2}$. They revealed photophysical and photochemical properties of the 8-hydroxy-pyrene-1,3,6-trisulfonate (HPTS) in ionic liquids, as well as the performance of the sensor for dissolved and gaseous $\mathrm{CO}_{2}$. Further, Ertekin et al. reported an optical $\mathrm{CO}_{2}$ sensor with ionic liquid-doped electrospun nanofibers based on the changes in the fluorescence signal intensity of an ion pair form of HPTS [49,50]. Further, Wolfbeis et al. performed semi-quantitative determination of $\mathrm{CO}_{2}$ by dissolving the $\mathrm{pH}$ indicators bromothymol blue, thymol blue, and HPTS along with a reference fluorophore in the silicone-ionic liquid emulsions [51]. Tang et al. reported a carbamate ionic liquid-based $\mathrm{CO}_{2}$ sensor based on the change in the fluorescence response [52]. Further, Pandey et al. developed a fluorescent $\mathrm{CO}_{2}$ sensor relying on the response of fluorophores 1,3-bis(1-pyrenyl)propane (BPP), 1,3-bis(1-pyrenyl)decane (BPD) and 6-(1-pyrenyl)hexyl-11-(1-pyrenyl)undecanoate (BPHU) [53].

Other than these optical-based sensing methods, electrochemical techniques are shown to have applications for $\mathrm{CO}_{2}$ sensing [58-70]. There are mainly three types of electrochemical sensors based on the measurement of redox current (amperometric), or the development of a potential (potentiometric), or a change in the electrical impedance (conductometric). In the case of amperometric sensors, the analyte species diffuses through the electrolyte to be detected at the working electrode surface [28,58,59]; whereas potentiometric sensors consist of a membrane that contains ion exchangers, lipophilic salts and plasticizers, and the trans-membrane potential affords the information of the activity of the analyte ion in solution. Ionic liquids are a better choice to replace conventional electrolyte systems in amperometric/potentiometric sensors due to their good electrical conductivity and, more importantly, to their wide electrochemical windows [39-42]. An electrochemical $\mathrm{CO}_{2}$ sensor consists of a working electrode with other electrodes (e.g., reference electrode) connected through an electrolyte, which is covered by a gas-permeable membrane. The gas passes through the membrane, diffuses through the electrolyte and is detected at the working electrode. It is shown that the ionic liquid-based electrochemical $\mathrm{CO}_{2}$ sensors reported so far are either based on the reaction between oxygen $\left(\mathrm{O}_{2}\right)$ and $\mathrm{CO}_{2}$ or on the reduction of $\mathrm{CO}_{2}$ gas within ionic liquids, or ionic liquid-polymer-based, or ionic liquid-nanomaterial-based systems. Compton et al. reported an electrochemical $\mathrm{CO}_{2}$ sensor based on the reduction of $\mathrm{CO}_{2}$ within ionic liquid 1-butyl-3-methylimidazolium acetate ([BMIM][Ac]) [60]. They made use of a two-electrode cell ( $\mathrm{Pt}$ as the working electrode and $\mathrm{Ag}$ as the reference electrode) for the chronoamperometric detection of $\mathrm{CO}_{2}$ within the ionic liquid. Further, they reported a voltammetric $\mathrm{CO}_{2}$ sensor based on the reduction of $\mathrm{O}_{2}$ in the presence of $\mathrm{CO}_{2}$ within two ionic liquids, 1-ethyl-3-methylimidazolium bis(trifluoromethylsulfonyl) imide ([EMIM][Tf $\left.{ }_{2} \mathrm{~N}\right]$ ) and hexyltriethylammonium bis(trifluoromethylsulfonyl)imide $\left(\left[\mathrm{N}_{6222}\right]\left[\mathrm{Tf}_{2} \mathrm{~N}\right]\right)$ [61]. Shimoyama et al. reported an electrochemical impedance-based $\mathrm{CO}_{2}$ gas sensor using an ionic gel formed by the mixture of an ionic liquid 1-ethyl-3-methyl-imidazolium tetrafluoroborate ([EMIM] $\left[\mathrm{BF}_{4}\right]$ ) and a polymer polyvinylidene fluoride-cohexafluoro propylene (PVDF-HFP) [62]. Further, they reported ionic liquid-based electrochemical $\mathrm{CO}_{2}$ sensors based on carbon nanotubes (CNTs) and graphene, respectively [66,67].

This review focuses on a detailed assessment into the applications of ionic liquids in optical and electrochemical sensors for the sensing of $\mathrm{CO}_{2}$ gas. 


\section{Ionic Liquids in Optical $\mathrm{CO}_{2}$ Sensors}

The use of ionic liquids in optical $\mathrm{CO}_{2}$ sensor development is explored by many researchers. In most cases, optical spectroscopic techniques (e.g., UV-VIS absorbance, fluorescence and surface plasmon resonance) have been used as tools for sensing $\mathrm{CO}_{2}$. A change in UV-VIS absorbance or reflectance or fluorescence emission intensity within ionic liquid-based systems forms the basis for $\mathrm{CO}_{2}$ detection.

Ertekin et al. reported a new optical $\mathrm{CO}_{2}$ sensor based on the change in the fluorescence signal of 8-hydroxypyrene-1,3,6-trisulfonic acid trisodium salt (HPTS) in ionic liquids [44]. Ionic liquids 1-methyl-3-butylimidazolium tetrafluoroborate $\left([\mathrm{MBIM}]\left[\mathrm{BF}_{4}\right]\right)$ and 1-methyl-3-butylimidazolium bromide ([MBIM] $[\mathrm{Br}])$ were used as matrix materials with HPTS in the above optical $\mathrm{CO}_{2}$ sensor. It was observed that the fluorescence intensity of HPTS at 519 and $521 \mathrm{~nm}$ decreased with the increasing concentrations of $\mathrm{CO}_{2}$ by $90 \%$ and $75 \%$ in ionic liquids [MBIM] [BF 4 ] and [MBIM][Br], respectively. The response times of the sensing reagents were observed to be in the range of 1-2 min for switching from $\mathrm{N}_{2}$ to $\mathrm{CO}_{2}$ and 7-10 min for switching from $\mathrm{CO}_{2}$ to $\mathrm{N}_{2}$. They also reported another optical $\mathrm{CO}_{2}$ sensor based on the spectrophotometric signal changes of another probe, a bromothymol blue/tetraoctylammonium $\left(\mathrm{BTB}^{-} / \mathrm{TOA}^{+}\right)$ion pair, in the same above ionic liquids [45]. This sensor was based on the determination of the acidity constant $\left(\mathrm{p} K_{\mathrm{a}}\right)$ of the modified BTB within the employed ionic liquids. Further, they proposed an emission-based $\mathrm{CO}_{2}$ sensor based on the response of an ion pair form of HPTS in ionic liquid 1-ethyl-3-methylimidazolium tetrafluoroborate $\left([\mathrm{EMIM}]\left[\mathrm{BF}_{4}\right]\right)$ containing ethyl cellulose $(\mathrm{EC})$ matrix [46]. The utilization of ionic liquid [EMIM] $\left[\mathrm{BF}_{4}\right]$ in ethyl cellulose matrix is seen to result in superior spectral characteristics, showing an atypical isoemmissive point in modified EC matrix at $418 \mathrm{~nm}$. Next, they developed an optical dissolved $\mathrm{CO}_{2}$ sensor based on the spectrofluorimetric signal changes of the fluorescent carbazole within the above [EMIM] $\left[\mathrm{BF}_{4}\right]^{-}$containing ethyl cellulose (EC) matrix [47]. It is important to mention that the above sensor shows a very good detection limit of $500 \mathrm{nM}$ in the form of $\left[\mathrm{HCO}_{3}\right]^{-}$for dissolved $\mathrm{CO}_{2}$.

The development of electrospun nanofiber-based optical $\mathrm{CO}_{2}$ sensors was first reported by Ertekin et al. [48-50]. They used polymethylmethacrylate (PMMA) and ethyl cellulose (EC) as polymeric materials and electrospinning to fabricate optical chemical sensing agents. Electrospinning is found to be a promising, simple and effective method for fabricating optical chemosensor devices. The authors optimized the conditions for electrospinning to form nodal-free PMMA or EC-based continuous nano-fibers by varying the concentrations of plasticizer dioctyl phthalate (DOP), PMMA or EC and ionic liquid 1-ethyl-3-methylimidazolium tetrafluoroborate ([EMIM][BF 4 ]) in the solutions. It was observed that the presence of the ionic liquid in the PMMA solutions facilitates the electrospinning of nodal-free nanofibers due to the high conductivity of the ionic liquid-doped precursor polymer solutions. This electrospun nanofiber-based optical $\mathrm{CO}_{2}$ sensor is based on the change in the fluorescence response of an ion pair form of 8-hydroxypyrene-1,3,6-trisulfonic acid (HPTS) in the presence of $\mathrm{CO}_{2}$ [48]. This sensor design showed high sensitivities due to the high surface area-to-volume ratio of the nanofibrous membrane structures. The results obtained from Stern-Volmer analysis show that the sensitivities of electrospun nanofibrous membranes to detect $\mathrm{CO}_{2}$ are 24-120-fold higher than those of the common thin film-based sensors. More importantly, it was observed that the response times of the sensing reagents were short, and the signal changes were fully reversible. The stability of the ion pair form of HPTS in the employed matrix materials was excellent, and when stored in the ambient air of the laboratory, no significant drift in signal intensity was observed, even after a few months. The presence of ionic liquid [EMIM] $\left[\mathrm{BF}_{4}\right]$ is seen to enhance the photostability of HPTS in the polymer matrix. The authors also reported another electrospun nanofiber for the detection of dissolved $\mathrm{CO}_{2}$ using the same ionic liquid [EMIM] $\left[\mathrm{BF}_{4}\right]$ [49]. In this work, they used a novel fluorescent indicator dye in ethyl cellulose-based plasticized matrix material in the form of electrospun nanofibers. Fluorescent dye $N^{\prime}$-[(E)-(4-nitrophenyl)methylidene]pyridine-4-carbohydrazide was doped together with ionic liquid [EMIM] $\left[\mathrm{BF}_{4}\right]$ in the presence of perfluoro acids for fluorescence detection of $\mathrm{CO}_{2}$. Further, they 
proposed a similar electrospun nanofiber-based $\mathrm{CO}_{2}$ sensor based on the spectrophotometric signal change of fluorophore bromothymol blue (BTB) [50]. The effect of ionic liquids with different anionic

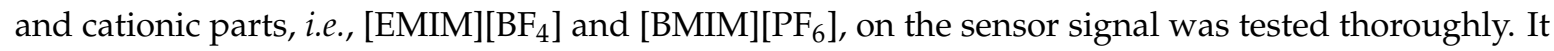
is noticed that fluorophore BTB also satisfies the requirement of a distinguishable color change to the naked eye when encapsulated in nanofibers. The above-described nanofiber-based $\mathrm{CO}_{2}$ sensor can be used for quantitative determination of $\mathrm{CO}_{2}$ in the concentration range of $0.0 \%-100.0 \% \mathrm{pCO}_{2}$. With respect to continuous thin films, the electrospun nanofibers are seen to have enhanced sensitivity extending to a $98 \%$ relative signal change, lower detection limits and shorter response times.

Wolfbeis et al. reported a novel optical $\mathrm{CO}_{2}$ sensor based on the emulsion of ionic liquids in a silicone matrix prepared from the mixture of tetravinyltetramethylcyclotetrasiloxane, vinylterminated PDMS and methylhydrosiloxane-dimethylsiloxane copolymer [51]. The ionic liquids used are 1-butyl-3-methylimidazolium tetrafluoroborate ([BMIM][ $\left.\left.\mathrm{BF}_{4}\right]\right)$ and 1-butyl-3-methylimidazolium tosylate ([BMIM][OTs]). Semiquantitative determination of $\mathrm{CO}_{2}$ was achieved from the UV-VIS absorption response of $\mathrm{pH}$ indicator thymol blue (TB) and bromothymol blue (BTB) and the fluorescence response of 8-hydroxypyrene-1,3,6-trisulfonate (HPTS) within the ionic liquids. It is noteworthy to mention that the sensitivity of the system can be determined by the $\mathrm{p} K_{\mathrm{a}}$ of the indicator used.

A carbamate ionic liquid-based fluorescent chemosensor for the detection and quantitation of carbon dioxide gas was developed by Tang et al. [52]. Initially, they noticed that hexaphenylsilole (HPS) is non-luminescent when it is dissolved in THF, but becomes strongly fluorescent when the HPS molecules are aggregated in the THF/water mixtures with high water contents (Figure 2A). They further observed that bubbling $\mathrm{CO}_{2}$ through an amine yields a carbamate ionic liquid (CIL), which is accompanied by increases in the polarity and viscosity of the medium. Keeping this in mind, an amine solution of HPS was purged with a stream of $\mathrm{CO}_{2}$ gas that turned on the light emission of HPS as its molecules clustered in and its restriction of the intramolecular rotation (RIR) process was activated by the polar and viscous CIL. A series of amines were tested, and it was shown that bubbling large volumes of $\mathrm{CO}_{2}$ gas through HPS solutions in piperidine (Pip), pyridine (Py), diethylamine (DEA) and butylamine (BA) caused no recognizable changes in the emission of HPS. However, a green light was emitted from a dipropylamine (DPA) solution of HPS immediately after it had been bubbled with a small volume of $\mathrm{CO}_{2}$ gas. Interestingly, the fluorescence intensity of HPS was seen to be increased on increasing the volume of $\mathrm{CO}_{2}$ gas. Further, a CIL was prepared by purging DPA with a large excess of $\mathrm{CO}_{2}$ gas. A monotonic increase in the fluorescence intensity was observed on increasing the amount of the CIL in DPA solution of HPS (Figure 2B). The plot of the fluorescence intensity $v s$. the concentration of CIL shows a linear trend, which clearly indicates that it is the CIL that has affected the fluorescence emission of HPS. In order to quantify the fraction of $\mathrm{CO}_{2}$ in a gas mixture, $\mathrm{CO}_{2} / \mathrm{N}_{2}$ mixtures were used as a model system to check how the fluorescence response of $\mathrm{HPS}$ varies with the concentration of $\mathrm{CO}_{2}$. The mixtures of $\mathrm{CO}_{2} / \mathrm{N}_{2}$ with varying $\mathrm{CO}_{2}$ concentrations were bubbled through HPS solutions in DPA at a fixed rate for a fixed time. It was noticed that the fluorescence intensity of HPS was increased monotonously with increasing concentration of $\mathrm{CO}_{2}$. The plot of log intensity vs. $\left[\mathrm{CO}_{2}\right]$ gives a straight line over the whole concentration range that enables quantification of $\mathrm{CO}_{2}$ under various conditions. It has been reported that bicarbonate is formed in the reaction of amine with $\mathrm{CO}_{2}$ in the presence of water [71]. As the conventional $\mathrm{CO}_{2}$-sensing processes are susceptible to water, moisturized $\mathrm{CO}_{2}$ gas was prepared to examine the effect of water on the performance of sensing. It is noticed that purging a DPA solution of HPS with the moisturized gas shows identical behavior to those obtained by using dry $\mathrm{CO}_{2}$ as the bubbling gas. Further, it is observed that the addition of water droplets into DPA solutions of HPS gives almost similar results. Hence, it became clear that the $\mathrm{CO}_{2}$-sensing process is not affected significantly by the presence of water. More importantly, the CIL-based sensing scheme is free of the CO-interfering problem, because it is well known that $\mathrm{CO}$ does not react with amine [72]. The overall principle of the above $\mathrm{CO}_{2}$-sensing mechanism lies in the fact that bubbling DPA liquid with $\mathrm{CO}_{2}$ gas results 
in the formation of a viscous and polar CIL with poor solvating power toward HPS. It is obvious that a viscous medium hinders intramolecular movement, and a polar solvent induces hydrophobic solutes to aggregate. These two effects activate the restriction of the intramolecular rotation process of HPS, thus blocking its nonradiative decay channels and turning on its light emission in the CIL mixture. Increases in $\mathrm{CO}_{2}$ concentration increase the viscosity and polarity, thus enabling the gas quantitation. This $\mathrm{CO}_{2}$-sensing scheme is observed to permit quantitation of $\mathrm{CO}_{2}$ amount over the whole concentration range $(0 \%-100 \%)$, and this can be highly appealing, particularly for the areas of seismology and volcanology, where field tracking of the gas mixtures with high amounts of $\mathrm{CO}_{2}$ plays a crucial role in disaster prediction and prevention.
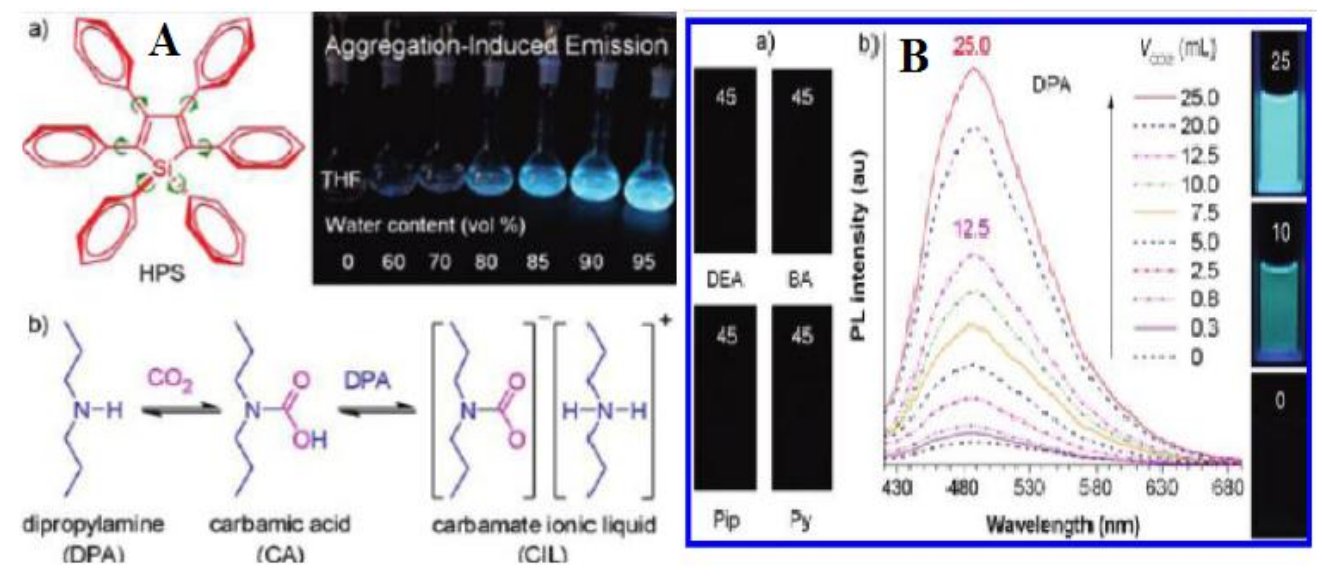
(CIL)

Figure 2. (A) (a) Hexaphenylsilole (HPS) is nonemissive when it is dissolved in THF, but becomes strongly fluorescent when the molecules are aggregated in the THF/water mixtures with high water contents; (b) the formation of carbamate ionic liquid (CIL) by bubbling $\mathrm{CO}_{2}$ gas through dipropylamine (DPA); (B) (a) Photographs of HPS solutions $(\sim 37 \mu \mathrm{M})$ in the amines $(2 \mathrm{~mL})$ bubbled with $\mathrm{CO}_{2}$ gas (45 mL); DEA = diethylamine; $\mathrm{BA}=$ butylamine; Pip = piperidine; $\mathrm{Py}=$ pyridine; (b) PL (Photoluminescence) spectra and photographs of HPS in DPA before and after bubbling with different volumes of $\mathrm{CO}_{2}\left(V_{\mathrm{CO} 2}\right)$. All of the photographs were taken under UV illumination ([52], reprinted (adapted) with permission from Tang B.Z. et al. (2010) J. Am. Chem. Soc. 132: 13951-13953. Copyright (2010) American Chemical Society).

Further, Pandey et al. reported a fluorescence excimer-based $\mathrm{CO}_{2}$ detection strategy using the above carbamate ionic liquid (CIL) system based on the modulation in the local viscosity and polarity within the system [53]. They prepared an optically-responsive switchable CIL by the reaction of two moles of dipropylamine (DPA) with one mole of $\mathrm{CO}_{2}$. As it was earlier shown that $\mathrm{CO}_{2}$ reacts with DPA to result in conversion into a CIL, the viscosity, as well as polarity of the medium changes significantly, which forms the basis of $\mathrm{CO}_{2}$ detection [52]. Taking into account these facts, the authors used excimer-forming fluorescence microviscosity probes 1,3-bis(1-pyrenyl)propane (BPP), 1,3-bis(1-pyrenyl)decane (BPD) and 6-(1-pyrenyl)hexyl-11-(1-pyrenyl)undecanoate (BPHU), respectively, for detection purposes. It is observed that the excimer-to-monomer fluorescence intensity ratio $\left(\mathrm{I}_{\mathrm{E}} / \mathrm{I}_{\mathrm{M}}\right)$ decreases linearly with the volume of $\mathrm{CO}_{2}$ to which the sample was subjected, thus clearly indicating an increase in the sample viscosity with the increase in $\mathrm{CO}_{2}$ volume. Furthermore, the $\mathrm{I}_{\mathrm{E}} / \mathrm{I}_{\mathrm{M}}$ ratio is observed to decrease linearly with the flow rate of $\mathrm{CO}_{2}$. Further, they used a solvatochromic probe, Reichardt's dye 30, whose absorption band maximum is known to be highly sensitive to both the dipolarity/polarizability and the hydrogen bond donating (HBD) acidity of the milieu. Interestingly, it is noticed that the dye behavior changes dramatically, showing different appearances in neat DPA (pale yellow) versus that in $\mathrm{CO}_{2}$-saturated DPA (deep purple). This is well supported by the results obtained from the UV-VIS absorbance spectral behavior of the above system. 
Based on the above principle of aggregation-induced emission (AIE) that allows molecules to switch from a non-fluorescent to a fluorescent nature, Wang et al. reported an amidine-based $\mathrm{CO}_{2}$ chemosensor [54]. The chosen amidine-based system became an ionic liquid with high viscosity by bubbling $\mathrm{CO}_{2}$ through it as a result of the reaction of amidine with $\mathrm{CO}_{2}$. A liquid mixture composed of tetraphenylethene (TPE), 5-amino-1-pentanol (APN) and 1,8-diazabi-cyclo-[5,4,0]-undec-7-ene (DBU) was prepared. TPE and DBU are amidine-containing molecules and show AIE. It was observed that after bubbling with a small volume of $\mathrm{CO}_{2}$, the TPE-containing mixture of DBU and APN (1:1, $\mathrm{v} / \mathrm{v}$ ) remained transparent and emitted strong fluorescence immediately. Interestingly, it was noticed that the intensity of fluorescence was increased linearly with the increase in the $\mathrm{CO}_{2}$ concentration, thus making it feasible to monitor the amount of $\mathrm{CO}_{2}$ quantitatively. Further, the same experiment was carried out with three different volume proportions of DBU to APN, 1:1, 2:1 and 3:1, respectively, to gain insight into the nature of the material. It was observed that the fluorescent intensity of the samples bubbled with $\mathrm{CO}_{2}$ for different times (i.e., 0-200 s) increased with increasing the purging time of $\mathrm{CO}_{2}$ for all three samples. The sample with a volume ratio of 1:1 was seen to exhibit a linear increase, as well as the strongest fluorescence intensity, as compared to the other two samples with proportions of 2:1 and 3:1, respectively. It is noteworthy that the aforementioned fluorescent chemosensor is observed to have unique sensitivity towards $\mathrm{CO}_{2}$, is free of $\mathrm{CO}$ interfering problems and has extraordinarily high water-resistant properties.

Yoon et al. developed a novel optical $\mathrm{CO}_{2}$ sensor that utilized tetrapropyl (TBBI)-based ionic liquids [55]. It was earlier shown that benzobisimidazolium (BBI)-based ionic liquids can act as biscarbene ligands for metal ions, and in some cases, these are found to be fluorescent, as well [73-75]. A key feature associated with the BBI-based fluorophores is that functionalization of the $C_{1}$ position of the imidazolium rings can tune their photophysical properties. Further, it was reported that $\mathrm{N}$-heterocyclic carbenes (NHCs), which are often obtained by deprotonating the corresponding imidazolium salts, are capable of activating $\mathrm{CO}_{2}$ to form imidazolium carboxylates [76,77]. Considering these factors, the authors imagined that the addition of fluoride anion, which acts as a weak base, would produce a species possessing a partial NHC character and, therefore, would allow for the reaction with $\mathrm{CO}_{2}$; the changes in the optical features would then enable detection. Keeping this in mind, a specific organic-soluble NHC precursor, i.e., tetrapropyl benzobisimidazolium salt (TBBI), was synthesized, and the TBBI solution in acetonitrile containing three equivalents of $\mathrm{F}^{-}$ions (added as the tetrabutylammonium salt, TBAF) was bubbled with $\mathrm{CO}_{2}$ gas. It was observed that on increasing volume of $\mathrm{CO}_{2}$ (governed by a mass flow controller), the fluorescence intensity gradually increased, and no additional changes in the emission intensity were observed after the mixture got saturated at a certain $\mathrm{CO}_{2}$ concentration. The aforementioned approach using TBBI-based ionic liquids effectively established a new method for optical detection of $\mathrm{CO}_{2}$ with fast response times, a low detection limit (ca. $30 \mathrm{ppm}$ for this system), very good sensitivity and provides for both fluorescence and colorimetric outputs. Further, they reported a fluorescent and colorimetric $\mathrm{CO}_{2}$ sensor using polydiacetylene (PDA)-functionalized imidazolium-based ionic liquid [56]. It was earlier reported that PDAs exhibit a color transition from blue to red that can be triggered when stimuli disrupt the effective polymer conjugation length, typically by inducing a change in the preferred backbone conformation [78]. This phenomenon associated with PDAs is seen to be highly useful in developing various chemosensors [78]. This sensor design relies on the same event, i.e., blue to red color phase change induced by the reaction of $\mathrm{CO}_{2}$ with alkylamines tethered to the imidazolium PDA. It was noticed that the reaction of the tethered amine with $\mathrm{CO}_{2}$ to form carbamoate salt releases a proton, which is then reacted to another amine molecule, and the generated ammonium ions are unreactive toward $\mathrm{CO}_{2}$. The positive charges of the ammonium ions neutralize the newly-formed anionic carbamoate sites, and hence, the aqueous solution of the PDA does not show any color change upon exposure to $\mathrm{CO}_{2}$ gas. However, the addition of an external base triethylamine (TEA) to the above system results in the formation of deprotonated ammonium carbamoate that does not interact with the PDA in the absence of $\mathrm{CO}_{2}$. This is clearly evident by the lack of change in its 
visible spectra and the unchanged blue color of the solution. Interestingly, a transform in the color from blue to red is immediately apparent when the above aqueous PDA solution in the presence of TEA is bubbled with a small volume of $\mathrm{CO}_{2}$ gas. This is well-supported by the results obtained from UV-VIS and fluorescence spectral changes of the system at different volumes of $\mathrm{CO}_{2}$. It is noteworthy that the cationic imidazolium groups play a significant role in the blue to red phase transition in the presence of $\mathrm{CO}_{2}$. When aqueous solutions of $\mathrm{PDA}-\mathrm{NH}_{2}$, having a backbone similar to that of the above PDA and primary amine side chains, but lacking imidazolium moieties, are bubbled with $\mathrm{CO}_{2}$ in the presence of TEA, the changes in the spectral behavior are observed to be negligible, and the original blue color remains unchanged. Hence, it is clear that the appended primary amines and the formation of carbamoate anions are not sufficient criteria to induce a PDA color transition. It is important to mention that the above PDA/TEA system is observed to be sufficiently sensitive toward atmospheric $\mathrm{CO}_{2}$ detection (ca. $400 \mathrm{ppm}$ ).

Other than the use of UV-VIS absorption and fluorescence emission-based methods for $\mathrm{CO}_{2}$ sensing, a report is found to have used surface plasmon resonance (SPR) for the detection of $\mathrm{CO}_{2}$ [57]. Shimoyama et al. designed a $\mathrm{CO}_{2}$ gas sensor using an SPR-based sensing scheme [79] with ionic liquid $[\mathrm{EMIM}]\left[\mathrm{BF}_{4}\right]$. These SPR sensors are generally based on the detection of the permittivity change of the specimen near the sensing surface. The authors fabricated the $\mathrm{CO}_{2}$ sensor using an

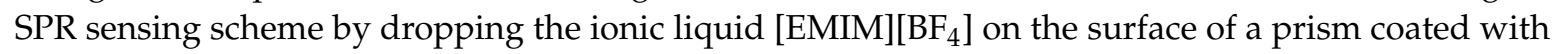
an $\mathrm{Au}$ thin layer. Ionic liquid [EMIM] $\left[\mathrm{BF}_{4}\right]$ was used, as it has selective absorbability towards $\mathrm{CO}_{2}$ gas. It was observed that the permittivity of the liquid increased when it absorbs $\mathrm{CO}_{2}$ gas. This change in permittivity on changing the concentration of $\mathrm{CO}_{2}$ was clearly detected by the SPR sensing scheme that forms the basis of $\mathrm{CO}_{2}$ detection. Since an SPR dip angle shifts by the change in the permittivity of the specimen, it is noticed that the SPR dip angle of the above sensor shifts when $\mathrm{CO}_{2}$ gas is absorbed. It is noteworthy that the above proposed SPR sensor can measure $\mathrm{CO}_{2}$ gas with a concentration as low as $700 \mathrm{ppm}$.

\section{Ionic Liquids in Electrochemical $\mathrm{CO}_{2}$ Sensors}

In addition to ionic liquid-based optical $\mathrm{CO}_{2}$ sensors, reports also exist on the ionic liquid-based detection of $\mathrm{CO}_{2}$ that utilizes electrochemical methods.

Compton et al. reported an ionic liquid-based electrochemical $\mathrm{CO}_{2}$ sensor that utilizes the reduction of $\mathrm{CO}_{2}$ in the ionic liquid [BMIM] [acetate] [60]. They used a two-electrode cell with a 10-mm diameter Pt working electrode and a 0.5-mm diameter Ag quasi-reference electrode. Microscale samples of the ionic liquid [BMIM] [acetate] containing the cobaltocenium/cobaltocene $\left(\mathrm{Cc}^{+} / \mathrm{Cc}\right)$ as the internal reference were held under vacuum conditions to remove water and other gaseous solutes before being exposed to dry $\mathrm{CO}_{2}$. It was observed that $\mathrm{CO}_{2}$ in [BMIM] [acetate] was reduced to the radical anion at $-1.3 \mathrm{~V}$ versus $\mathrm{Cc}^{+} / \mathrm{Cc}$. It is important to mention that in the acetate ionic liquid, $\mathrm{CO}_{2}$ was reduced chemically and irreversibly via one electron transfer followed by the formation of possibly oxalate ion, carbon monoxide and/or carbonate ion. A high solubility $(1520 \mathrm{mM})$ of $\mathrm{CO}_{2}$ gas in the ionic liquid was determined from chronoamperometry, whereas the diffusion coefficient measured was an order of magnitude less than that measured in other imidazolium ionic liquids. It is surprising considering the viscosities of the liquids $(112,140$ and $371 \mathrm{cP}$ for imidazolium ionic liquids with $\left[\mathrm{BF}_{4}\right]^{-}$, [acetate $]^{-}$and $\left[\mathrm{PF}_{6}\right]^{-}$anions, respectively, at $298 \mathrm{~K}$ ), where in the absence of any follow-up chemical processes, the least viscous ionic liquid is expected to present the fastest diffusion. The reason for enhanced solubility and slowed diffusion is likely due to the chemical complexation of $\mathrm{CO}_{2}$ in [BMIM] [acetate], thus demonstrating a means for the possible sequestration of $\mathrm{CO}_{2}$ gas. Further, authors reported an electrochemical gas sensor for the detection of $\mathrm{CO}_{2}$ gas based on the reduction of oxygen $\left(\mathrm{O}_{2}\right)$ in the presence of $\mathrm{CO}_{2}$ at a gold microdisk electrode in ionic liquids 1-ethyl-3-methylimidazolium bis(trifluoromethylsulfonyl)imide ([EMIM][Tf $\left.{ }_{2} \mathrm{~N}\right]$ ) and hexyltriethylammonium bis(trifluoromethylsulfonyl)imide $\left(\left[\mathrm{N}_{6222}\right]\left[\mathrm{Tf}_{2} \mathrm{~N}\right]\right)$, respectively [61]. From the electrochemical studies, it was shown that on increasing concentration of $\mathrm{CO}_{2}$, cyclic voltammetry 
(CV) shows an increase in the reductive current and reduction of the oxidative current, indicating that the generated superoxide readily reacts with $\mathrm{CO}_{2}$. The reaction mechanism between superoxide and carbon dioxide involves the heterogeneous transfer of an electron to dioxygen at the gold working electrode surface. The above observation of the increase in the reductive current on addition of $\mathrm{CO}_{2}$ likely results from slower reaction kinetics in the ionic liquid medium as compared to that in conventional aprotic solvents due to the relatively higher viscosity associated with ionic liquids. They have also determined the diffusion coefficient $\left(2.3 \times 10^{-10} \mathrm{~m}^{2} / \mathrm{s}\right)$ and solubility $(55 \mathrm{mM})$ of $\mathrm{CO}_{2}$ within ionic liquid $\left[\mathrm{N}_{6222}\right]\left[\mathrm{Tf}_{2} \mathrm{~N}\right]$ using chronoamperometry. The $\mathrm{CO}_{2}$ solubility is observed to be relatively high as compared to more traditional aprotic solvent media, thus suggesting that ionic liquid-based systems may be more advantageous for the detection of such gases.

Ishizu et al. have reported an electrochemical $\mathrm{CO}_{2}$ gas sensor based on an ionic gel formed by mixing of ionic liquid 1-ethyl-3-methylimidazolium tetrafluoroborate ([EMIM][BF $]$ ) and polymer polyvinylidene fluoride-co-hexafluoro propylene (PVDF-HFP) [62]. An organic solvent $\mathrm{N}, \mathrm{N}$-dimethyl acetamide (DMAC) was used to dissolve [EMIM] $\left[\mathrm{BF}_{4}\right]$ and PVDF-HFP in the formation of the gel, because PVDF-HFP was insoluble in neat $\left[\mathrm{EMIM}\left[\mathrm{BF}_{4}\right]\right.$. Finally, DMAC was evaporated by heating the solution to form the ionic liquid gel. The above-prepared [EMIM] $\left[\mathrm{BF}_{4}\right]$-based ionic gel was patterned onto the electrodes. The thickness of the ionic gel was observed to be dozens of times thinner than that of the neat $[\mathrm{EMIM}]\left[\mathrm{BF}_{4}\right]$ droplet due to the lower viscosity associated with the gel as compared to the neat ionic liquid. Ionic liquid [EMIM] $\left[\mathrm{BF}_{4}\right]$ was chosen for the ionic gel-based $\mathrm{CO}_{2}$ sensor, as it was observed that $[\mathrm{EMIM}]\left[\mathrm{BF}_{4}\right]$ selectively absorbs $\mathrm{CO}_{2}$ gas. The above electrochemical $\mathrm{CO}_{2}$ sensor consisted of two Pt electrodes patterned under the ionic gel. The concentration of $\mathrm{CO}_{2}$ gas was detected by measuring the change in the electrochemical impedance between these two electrodes. The observed change in the electrochemical impedance was mainly due to the chemical reaction taking place on electrodes in response to the absorption of $\mathrm{CO}_{2}$ gas. Earlier, Rosen $e t$ al. investigated the chemical reaction taking place as a result of an applied potential to $[\mathrm{EMIM}]\left[\mathrm{BF}_{4}\right]$ in $\mathrm{CO}_{2}$-containing atmosphere $[80,81]$. They have shown that the increase in the concentration of $\mathrm{CO}_{2}$ gas enhances the reduction on the cathode because the cation of the ionic liquid [EMIM] worked as a catalyst in the $\mathrm{CO}_{2}$ gas reduction. Further, they have observed that the reduction occurred only when the applied electrical potential to $[\mathrm{EMIM}]\left[\mathrm{BF}_{4}\right]$ was within a certain range. The above ionic gel-based electrochemical $\mathrm{CO}_{2}$ sensor relies on the same sensing principle reported by Rosen et al. The change in the electrical impedance is observed to be dependent on the concentration of $\mathrm{CO}_{2}$ gas and the applied voltage. To examine the reaction between the ionic gel and $\mathrm{CO}_{2}$ gas on the electrode, the authors conducted experiment using a potentiostat/galvanostat by applying a DC voltage to the cell in the range of $0-3.0 \mathrm{~V}$ and measuring the current flowing through the cell. They have shown that the current change took place in the range $0.5-2.5 \mathrm{~V}$ and that the observed change was caused by the $\mathrm{CO}_{2}$ gas reduction that occurred near the electrodes. More importantly, it is observed that this reaction is anticipated to lead to the change of the cell's impedance, as well. The observed impedance change rate is seen to be proportionally decreasing with the increase in the concentration of $\mathrm{CO}_{2}$ gas. Finally, the authors examined the sensitivity of the above ionic gel-based $\mathrm{CO}_{2}$ sensor and observed that the above impedance-based electrochemical sensor can measure the difference of a $500-\mathrm{ppm} \mathrm{CO}_{2}$ gas concentration by using a power as small as $0.65 \mu \mathrm{W}$. Further, Shimoyama et al. proposed a low power consumption electrochemical $\mathrm{CO}_{2}$ gas sensor using some imidazolium-based ionic liquids [63]. The electrical impedance of the ionic liquids was observed to decrease with the increase in the concentration of $\mathrm{CO}_{2}$ gas. Thus, the authors have proposed that the $\mathrm{CO}_{2}$ gas concentration of the atmosphere can be easily estimated by measuring the impedance of the ionic liquids. This sensor device has a power consumption of several tens of microwatts only and is lower than the conventional sensor by $1 / 1000$. The resolution of the above proposed sensor was found to be $100 \mathrm{ppm}$ with a short detection time. This electrochemical $\mathrm{CO}_{2}$ senor has low power consumption and, hence, can be applied for green energy management. 
Zeng et al. designed an in situ electrochemical quartz crystal microbalance (EQCM)-based $\mathrm{CO}_{2}$ sensor, which utilized electrochemical reactions between $\mathrm{O}_{2}$ and $\mathrm{CO}_{2}$ in three structurally-different ionic liquids: 1-butyl-3-methylimidazolium bis(trifluoromethanesulfonyl)imide ([BMIM][Tf $\left.{ }_{2} \mathrm{~N}\right]$ ), 1-butyl-2,3-dimethylimidazolium bis(trifluoromethanesulfonyl)imide ([BdMIM][Tf $\left.\left.{ }_{2} \mathrm{~N}\right]\right)$ and 1-butyl-1methylpyrrolidinium bis(trifluoromethanesulfonyl)imide ([BMPY][Tf $\left.{ }_{2} \mathrm{~N}\right]$ ) [64]. They observed that the QCM integrated with the electrochemical method is significantly more sensitive and powerful for the characterization of the subtle differences (mass change or viscoelastic change) on the ionic liquid/electrode interface as compared to the single electrochemical method. In the formation of the sensor, ionic liquids were drop-coated onto the working electrode made up of $\mathrm{Au}$ quartz crystal, and platinum wire and silver wire were used as the counter electrode and quasi-reference electrode, respectively. All potentials were measured using $\mathrm{Fc} / \mathrm{Fc}^{+}$( $50 \mu \mathrm{M}$ ferrocene $(\mathrm{Fc})$ in ionic liquids) as the internal reference. From the cyclic voltammetric $(\mathrm{CV})$ response, it was noticed that in the absence of $\mathrm{O}_{2}, \mathrm{CO}_{2}$ was reduced via a chemically-irreversible one electron transfer to $\mathrm{CO}_{2}{ }^{\bullet-}$ radical anion at around $-2.3 \mathrm{~V}$ vs. $\mathrm{Fc} / \mathrm{Fc}^{+}$. More importantly, the cathodic peak current was seen to increase linearly with the increase in $\mathrm{CO}_{2}$ concentration. In the presence of $\mathrm{O}_{2}$, the cathodic peak current for the first cycle at $-1.2 \mathrm{~V}$ increases, whereas the corresponding anodic peak for superoxide re-oxidation decreases, thus suggesting that the generated superoxide rapidly reacts with $\mathrm{CO}_{2}$. It was observed that the typical voltammetric response for $\mathrm{CO}_{2}$ at $-2.3 \mathrm{~V}$ remained absent. From the above $\mathrm{CV}$ results, it is clear that the reaction of $\mathrm{CO}_{2}$ and superoxide has taken place rapidly, and there is a competition between ionic liquid cations and $\mathrm{CO}_{2}$ to react with the electrochemically-generated superoxide. It was noticed that $\mathrm{CO}_{2}$ reduction in ionic liquids is irreversible and forms $\mathrm{CO}_{2}{ }^{--}$adsorbate at the electrode interface. On increasing the concentrations of $\mathrm{CO}_{2}$, the reduction of $\mathrm{O}_{2}$ is switched from a one-electron process to an overall two-electron process and forms adsorbed $\mathrm{CO}_{2}{ }^{--}$intermediate species. Even though the mechanisms of the electrochemical reaction between $\mathrm{CO}_{2}$ and electrochemically-generated superoxide radical $\left(\mathrm{O}_{2}{ }^{\bullet-}\right)$ are found to be similar in all three ionic liquids, simultaneously performed EQCM experimental results show that the structurally different cation-based ionic liquids can modify the kinetics of the electrode reactions of $\mathrm{O}_{2}$ and $\mathrm{CO}_{2}$ due to a competition between the ionic liquid cation and $\mathrm{CO}_{2}$ to react with $\mathrm{O}_{2}{ }^{\bullet-}$. It was observed that the reactivity of $\mathrm{O}_{2}{ }^{\bullet-}$ toward $\mathrm{CO}_{2}$ follows the order of the stability of the ionic liquid cation under the $\mathrm{O}_{2}{ }^{\bullet-}$ attack as $[\mathrm{BMPY}]\left[\mathrm{Tf}_{2} \mathrm{~N}\right]>\left[\mathrm{BdMIM}^{-}\left[\mathrm{Tf}_{2} \mathrm{~N}\right]>\right.$ [BMIM][Tf $\left.{ }_{2} \mathrm{~N}\right]$. This EQCM technique-based sensor is found to be a very good tool for $\mathrm{CO}_{2}$ detection in terms of the electrochemical reduction of $\mathrm{CO}_{2}$ in ionic liquids.

Further, Masel et al. reported an ionic liquid-based microfabricated $\mathrm{CO}_{2}$ sensor that operates at room temperature with very low power input [65]. The device uses the selective adsorption of $\mathrm{CO}_{2}$ in ionic liquid 1-ethyl-3-methylimidazolium tetrafluoroborate ([EMIM][BF 4 ) followed by an electrochemical reaction at a gold electrode to detect the presence of $\mathrm{CO}_{2}$. The sensor substrate was made from a 100-mm silicon wafer on which a 500-nm thermal oxide layer was grown. On the silicon wafer, 17-nm chromium and 100-nm gold layers were deposited as electrodes. A small droplet of the ionic liquid was painted between the source and drain electrodes. The [EMIM] $\left[\mathrm{BF}_{4}\right]$ droplet was painted over the entire lateral surface of the junction to protect the electroactive portion of the sensor. The potential between the source and the drain electrode was scanned from 0-5.5 V at a scan rate of $100 \mathrm{mV} / \mathrm{s}$. The sensing mechanism for this ionic liquid-based microfabricated sensor is based on the reduction of $\mathrm{CO}_{2}$ at the cathode and the subsequent oxidation of that species at the anode. It was observed that the device can measure normal atmospheric levels of $\mathrm{CO}_{2}$ with high reliability using less than $10 \mu \mathrm{W}$ of power. It is important to mention that the low selectivity of [EMIM] $\left[\mathrm{BF}_{4}\right]$ to $\mathrm{O}_{2}$ as compared to $\mathrm{CO}_{2}$ diminishes the effect of atmospheric oxygen on the sensor performance.

In addition to the above ionic liquid-based electrochemical $\mathrm{CO}_{2}$ sensors, few reports are found on the use of nanomaterial combined with ionic liquid for the detection of $\mathrm{CO}_{2}$ gas [66-69]. Shimoyama et al. proposed a gas sensor using a combination of carbon nanotubes (CNTs) and ionic liquid 1-ethyl-3-methyl imidazolium tetrafluoroborate ([EMIM][BF $\left.{ }_{4}\right]$ ) [66]. In this study, the authors 
selectively used ionic liquid [EMIM] $\left[\mathrm{BF}_{4}\right]$ and polymer polyethyleneimine (PEI), as both of these materials specially absorb $\mathrm{CO}_{2}$ gas. The ionic liquid [EMIM] $\left[\mathrm{BF}_{4}\right]$ or the mixture of $[\mathrm{EMIM}]\left[\mathrm{BF}_{4}\right]$ and PEI dropped on the CNT-FET were applied as a CNT-FET ionic liquid-gate and a surface modification material of CNTs. They proposed that by using the liquid gate, a gate voltage can be applied to the interface between CNTs and the ionic liquid efficiently. It is shown that when ionic liquid [EMIM] $\left[\mathrm{BF}_{4}\right]$ on the CNT-FET absorbs $\mathrm{CO}_{2}$ gas, $\mathrm{CO}_{2}$ reacts with water and PEIs and changes to ions. When a voltage was applied to the ionic liquid, the ions were attracted on to the CNT surface, and thus, CNTs were affected by the change around their surface. The authors proposed that $\mathrm{CO}_{2}$ gas can be easily detected by the measurement of the change resulted from the source/drain current flowing through the CNTs. When the ionic liquid absorbs specific gases, the ion types and concentrations change. Applying a voltage to the ionic liquid gate that attracts the ions onto the CNT surface results in the change of the CNT I-V property, and this helps in quantifying the $\mathrm{CO}_{2}$ concentration. Overall, it is demonstrated that $\mathrm{CO}_{2}$ could be effectively detected by the measure of the CNTs resistance change using the mixture of $[\mathrm{EMIM}]\left[\mathrm{BF}_{4}\right]$ and PEI. The authors proposed that this result was different from that using pure $[\mathrm{EMIM}]\left[\mathrm{BF}_{4}\right]$. Use of an ionic liquid-polymer mixture decreased the CNT resistance, because the amino group of PEI transferred charges to the CNTs. Further, the authors reported a $\mathrm{CO}_{2}$ gas sensor based on a field-effect transistor (FET) with a graphene channel and ionic liquid gate [67]. Graphene is observed to be supremely sensitive to its surroundings due to its high carrier mobility and surface-to-volume ratio. It is shown that the current-voltage characteristic of the graphene-FET changed in proportion to the logarithm of $\mathrm{CO}_{2}$ concentration. The proposed grapheme FET-based sensor selectively detects low concentrations of $\mathrm{CO}_{2}$ gas at a low gate voltage. The above device is able to detect $4000 \mathrm{ppm}$ of $\mathrm{CO}_{2}$ at a gate voltage below $1 \mathrm{~V}$. Further, the authors have proposed that optimization of the FET design and ionic liquid configuration can improve its sensitivity for $\mathrm{CO}_{2}$ detection.

Jin et al. have used poly-ionic liquid (PIL)-wrapped single-walled carbon nanotubes for $\mathrm{CO}_{2}$ sensing [68]. In the design of the sensor, they synthesized PIL poly[1-(4-vinylbenzyl)-3methylimidazolium tetrafluoroborate] by a conventional free-radical polymerization method from polymeric ionic liquid monomer. Further, they prepared a homogenous suspension of PIL-wrapped single-walled carbon nanotubes (SWNTs) by grinding SWNT powder in concentrated PIL solution. This PIL-wrapped SWNT electrochemical sensor exhibited superior sensitivity toward $\mathrm{CO}_{2}$ with a very low detection limit of 500 ppt. This $\mathrm{CO}_{2}$ sensor is found to be reproducible, highly selective and resistant to the interference of relative humidity and offers promising potential for real-time monitoring of $\mathrm{CO}_{2}$ with high sensitivity in some special circumstances. Further, Koziej et al. proposed a $\mathrm{CO}_{2}$ sensor based on tetraalkylammonium-based poly(ionic liquids) (PILs) that are able to absorb particularly large amounts of $\mathrm{CO}_{2}$ [69]. The authors used poly[( $p$-vinylbenzyl)-trimethylammonium hexafluorophosphate] (P[VBTMA][PF 6$]$ ) along with inorganic nanoparticles lanthanide-oxycarbonates $\left(\mathrm{La}_{2} \mathrm{O}_{2} \mathrm{CO}_{3}\right)$, having an outstanding $\mathrm{CO}_{2}$ adsorption capacity. In the design of the sensor, they engineered highly conductive channels localized at the interface between P[VBTMA] $\left[\mathrm{PF}_{6}\right]$ and $\mathrm{La}_{2} \mathrm{O}_{2} \mathrm{CO}_{3}$ nanoparticles. In this approach, the key aspect lies in precise tuning of the conductivity of the composites by taking advantage of the synergistic interaction at the interface between $\mathrm{P}[\mathrm{VBTMA}]\left[\mathrm{PF}_{6}\right]$ and $\mathrm{La}_{2} \mathrm{O}_{2} \mathrm{CO}_{3}$ nanoparticles. It was observed that the above composites with $70 \mathrm{wt} \% \mathrm{La}_{2} \mathrm{O}_{2} \mathrm{CO}_{3}$ show a decrease in the resistance (implying an increase in conductance, measured from electrical impedance spectroscopy) when exposed to $\mathrm{CO}_{2}$ at room temperature and in humid conditions. These composites show a further increase in the conductivity when exposed to pulses of $\mathrm{CO}_{2}$ between 150 and $2400 \mathrm{ppm}$. This work provides a simple strategy to achieve an enhancement of the electrical properties required for the utilization of PIL-based $\mathrm{CO}_{2}$ sensors. 


\section{Ionic Liquid-Induced Electrochemiluminescence in $\mathrm{CO}_{2}$ Sensing}

In addition to the above ionic liquid-based $\mathrm{CO}_{2}$ sensors where the detection scheme is based solely on either optical (mostly luminescence based) or electrochemical methods, a report is found on electrochemiluminescence-based detection of $\mathrm{CO}_{2}$, where a combination of both optical and electrochemical methods is used [70]. Chi et al. proposed a $\mathrm{CO}_{2}$ sensor based on ionic liquid-induced electrochemiluminescence (ECL) [70]. ECL is a combined process of electrochemistry and chemiluminescence in which species generated at the electrode surface undergo electron-transfer reactions to form excited states that emit light $[82,83]$. ECL sensors are shown to have the advantages of both electrochemical- and chemiluminescence-based sensors, such as high sensitivity, simple instrumentation and easy control $[82,83]$. In this ECL-based $\mathrm{CO}_{2}$ sensor, the authors have shown that the electrochemiluminescence of the luminol- $\mathrm{O}_{2}$ system in an electrolyte-free solution of $\mathrm{N}, \mathrm{N}$-dimethylformamide (DMF) and dipropylamine (DPA) is induced by the formation of a carbamate ionic liquid (CIL) from the reaction between $\mathrm{CO}_{2}$ and DPA, which forms the basis of ECL-based $\mathrm{CO}_{2}$ detection (Figure 3A).

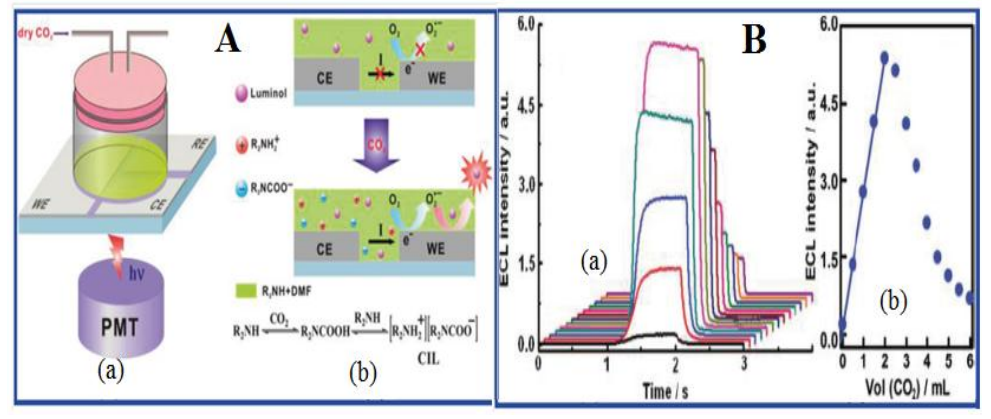

Figure 3. (A) (a) The schematic diagram of the electrochemiluminescence (ECL) sensor for $\mathrm{CO}_{2}$ and (b) the principle of the $\mathrm{CO}_{2}$ sensor based on ionic liquid-induced ECL; (B) (a) ECL responses of luminol- $\mathrm{O}_{2}$ obtained after injecting various volumes of $\mathrm{CO}_{2}(100 \mathrm{v} / \mathrm{v} \%)$ and (b) plots of ECL intensity vs. the volume of $\mathrm{CO}_{2}(100 \mathrm{v} / \mathrm{v} \%)$. ([70] reprinted (adapted) with permission from Chi Y. et al. (2011) Anal. Chem. 83: 6862-6867. Copyright (2011) American Chemical Society). CIL, carbamate ionic liquid.

In this sensor design, luminol acts as the ECL luminophore, and the maximum ECL response was found at a 1:1 volume ratio of DPA to DMF that is used for solubilizing luminol. It is important to mention that no current and ECL emission were observed from such a sensing solution containing luminol, DPA and DMF in the absence of $\mathrm{CO}_{2}$, since no conductive ion exists in the solution. However, the injection of $\mathrm{CO}_{2}$ gas into the above system leads to the reaction between $\mathrm{CO}_{2}$ and DPA to form a conductive CIL that induces strong ECL reactions of the luminol- $\mathrm{O}_{2}$ system. It was shown that when dry and pure $\mathrm{CO}_{2}$ were injected into the luminol- $\mathrm{O}_{2}$ ECL system at a fixed flow rate, the ECL response of the luminol- $\mathrm{O}_{2}$ system is linearly dependent on the $\mathrm{CO}_{2}$ concentration before getting saturated after reaching the optimum $\mathrm{CO}_{2}$ concentration. The ECL intensity was observed to increase with increasing the amount of $\mathrm{CO}_{2}$ in the range of $0-2.0 \mathrm{~mL}$ and then reaches a maximum at $2.0 \mathrm{~mL}$ followed by a decrease with further injection of $\mathrm{CO}_{2}$ gas into the sensor (Figure 3B). It is noteworthy that the above ECL sensing method shows several advantages in the detection of $\mathrm{CO}_{2}$, such as high selectivity, high safety, a wide linear response range and good sensitivity. This ECL sensor can sense $\mathrm{CO}_{2}$ in a short time, allows quantification of $\mathrm{CO}_{2}$ over a wide concentration range and is free of interferences from other gases. This $\mathrm{CO}_{2}$ sensor was found to have a detection limit of $80 \mathrm{ppm}$. This is the first reported ionic liquid-induced ECL sensor for $\mathrm{CO}_{2}$ gas detection. 


\section{Conclusions}

A rapidly-emerging field in advanced sensor research involves the development of sensors and diagnostic devices centered on ionic liquids as an alternative to molecular solvents and conventional materials for the detection and quantification of $\mathrm{CO}_{2}$. A cautionary note on the hygroscopic nature of the most ionic liquids must always be kept in mind. A thoroughly dried ionic liquid is desired in $\mathrm{CO}_{2}$ sensing applications to minimize water- $\mathrm{CO}_{2}$ interactions. Further, the thermal stability of ionic liquids for $\mathrm{CO}_{2}$ applications must be considered critically, as many ionic liquids show a significantly lower thermal stability than inorganic materials. It is also important to mention in this context that temperature also affects the viscosity of the medium, which, in turn, may destabilize the sensor. The fact that an ionic liquid may be synthesized for a specific application by simply manipulating its key physicochemical properties as a result of the appropriate selection of cation and anion combinations should also be considered carefully. The manipulation of the physicochemical properties of the ionic liquids is not simple, as in several instances, the cation/anion combinations do not afford desired outcomes. Finally, it is important to mention that the use of ionic liquids in the sensing of biomolecules is in its early stages. However, the rapid growth in this field is fairly evident from the current literature. This review highlights the use of ionic liquids as both optical and electrochemical $\mathrm{CO}_{2}$ sensors. Most of the optical-based $\mathrm{CO}_{2}$ sensors are shown to have used fluorescence emission as the important tool, and some reports are found to use UV-VIS absorbance and surface plasmon resonance (SPR) for $\mathrm{CO}_{2}$ detection. Most of the electrochemical $\mathrm{CO}_{2}$ sensors are based on cyclic voltammetry (showing a change in $I-V$ response), amperometry (based on current change) and electrical impedance (based on the change in resistance) measurements. It is important to highlight that not all of the $\mathrm{CO}_{2}$ sensors are purely ionic liquid based; some of them utilize other materials, along with ionic liquids, such as polymers, nanomaterials and several other appropriate compounds, for the detection of $\mathrm{CO}_{2}$. The sensing mechanisms of the ionic liquid-based $\mathrm{CO}_{2}$ sensors are described in detail in this review. The principle, design, sensitivity and detection limits are also highlighted. This review is supposed to be helpful to researchers working in the area of ionic liquids, as well as $\mathrm{CO}_{2}$ detection.

Acknowledgments: Siddharth Pandey acknowledges generous funding from the Department of Science and Technology (DST), Government of India, and the Council of Scientific and Industrial Research (CSIR), Government of India, for research on ionic liquids in his group. Anu Kadyan thanks the University Grants Commission (UGC), Government of India, for her fellowship.

Conflicts of Interest: The authors declare no conflict of interest.

\section{References}

1. Welton, T. Room-Temperature Ionic Liquids. Solvents for Synthesis and Catalysis. Chem. Rev. 1999, 99, 2071-2083. [CrossRef] [PubMed]

2. Plechkova, N.V.; Seddon, K.R. Applications of ionic liquids in the chemical industry. Chem. Soc. Rev. 2008, 37, 123-150. [CrossRef] [PubMed]

3. Pandey, S. Analytical applications of room-temperature ionic liquids: A review of recent efforts. Anal. Chim. Acta. 2006, 556, 38-45. [CrossRef] [PubMed]

4. Koel, M. Ionic liquids in chemical analysis. Cr. Rev. Anal. Chem. 2005, 35, 177-192. [CrossRef]

5. Baker, G.A.; Baker, S.N.; Pandey, S.; Bright, F.V. An analytical view of ionic liquids. Analyst 2005, 130, 800-808. [CrossRef] [PubMed]

6. Mallakpour, S.; Dinari, M. Ionic liquids as green solvents: Progress and prospects. In Green Solvents II; Rogers, R.D., Seddon, K.R., Eds.; Springer: Heidelberg, Germany, 2003.

7. Seddon, K.R. Ionic liquids: A taste of the future. Nat. Mater. 2003, 2, 363-365. [CrossRef] [PubMed]

8. Zhang, S.; Sun, N.; He, X.; Lu, X.; Zhang, X. Physical Properties of Ionic Liquids: Database and Evaluation. J. Phys. Chem. Ref. Data 2006, 35, 1475-1517. [CrossRef]

9. Wasserscheid, P. Chemistry: Volatile times for ionic liquids. Nature 2006, 439, 797. [CrossRef] [PubMed] 
10. Greaves, T.L.; Drummond, C.J. Protic ionic liquids: Properties and applications. Chem. Rev. 2008, 108, 206-237. [CrossRef] [PubMed]

11. Hallett, J.P.; Welton, T. Room-Temperature Ionic Liquids: Solvents for Synthesis and Catalysis. Chem. Rev. 2011, 111, 3508-3576. [CrossRef] [PubMed]

12. Van-Rantwijk, F.; Sheldon, R.A. Biocatalysis in ionic liquids. Chem. Rev. 2007, 107, 2757-2785. [CrossRef] [PubMed]

13. Huddleston, J.G.; Willauer, H.D.; Swatloski, R.P.; Visser, A.E.; Rogers, R.D. Room temperature ionic liquids as novel media for clean liquid-liquid extraction. Chem. Commun. 1998, 16, 1765-1766. [CrossRef]

14. Behera, K.; Dahiya, P.; Pandey, S. Effect of Added Ionic Liquid on Aqueous Triton X-100 Micelles. J. Colloid Interface Sci. 2007, 307, 235-245. [CrossRef] [PubMed]

15. Galinski, M.; Lewandowski, A.; Stepniak, I. Ionic liquids as electrolytes. Electrochim. Acta. 2006, 51, 5567-5580. [CrossRef]

16. Pearson, A.; O'Mullane, A.P.; Bansal, V.; Bhargava, S.K. Galvanic replacement mediated transformation of $\mathrm{Ag}$ nanospheres into dendritic Au-Ag nanostructures in the ionic liquid [BMIM][BF 4 ]. Chem. Commun. 2010, 46, 731-733. [CrossRef] [PubMed]

17. Behera, K.; Malek, N.I.; Pandey, S. Visual Evidence for Formation of Water-in-Ionic Liquid Microemulsions. ChemPhysChem 2009, 10, 3204-3208. [CrossRef] [PubMed]

18. Antonietti, M.; Kuang, D.; Smarsly, B.; Zhou, Y. Ionic liquids for the convenient synthesis of functional nanoparticles and other inorganic nanostructures. Angew. Chem. 2004, 43, 4988-4992. [CrossRef] [PubMed]

19. Wang, P.; Zakeeruddin, S.M.; Comte, P.; Exnar, I.; Grätzel, M. Gelation of ionic liquid-based electrolytes with silica nanoparticles for quasi-solid-state dye-sensitized solar cells. J. Am. Chem. Soc. 2003, 125, 1166-1167. [CrossRef] [PubMed]

20. Kubo, W.; Kitamura, T.; Hanabusa, K.; Wada, Y.; Yanagid, S. Quasi-solid-state dye-sensitized solar cells using room temperature molten salts and a low molecular weight gelator. Chem. Commun. 2002, 4, 374-375. [CrossRef]

21. Seki, S.; Kobayashi, Y.; Miyashiro, H.; Ohno, Y.; Usami, A.; Mita, Y.; Watanabe, M.; Terada, N. Highly reversible lithium metal secondary battery using a room temperature ionic liquid/lithium salt mixture and a surface-coated cathode active material. Chem. Commun. 2006, 5, 544-545. [CrossRef] [PubMed]

22. Sato, T.; Masuda, G.; Takagi, K. Electrochemical properties of novel ionic liquids for electric double layer capacitor applications. Electrochim. Acta. 2004, 49, 3603-3611. [CrossRef]

23. Wei, S.; Dandan, W.; Ruifang, G.; Kui, J. Direct electrochemistry and electrocatalysis of hemoglobin in sodium alginate film on a bmim PF6 modified carbon paste electrode. Electrochem. Commun. 2007, 9, 1159-1164. [CrossRef]

24. Xiong, H.Y.; Chen, T.; Zhang, X.H.; Wang, S.F. Electrochemical property and analysis application of biosensors in miscible nonaqueous media-Room temperature ionic liquid. Electrochem. Commun. 2007, 9, 1648-1654. [CrossRef]

25. Wang, S.F.; Xiong, H.Y.; Zeng, Q.X. Design of carbon paste biosensors based on the mixture of ionic liquid and paraffin oil as a binder for high performance and stabilization. Electrochem. Commun. 2007, 2, 807-812. [CrossRef]

26. Qin, W.; Li, S.F.Y. Determination of ammonium and metal ions by capillary electrophoresis-potential gradient detection using ionic liquid as background electrolyte and covalent coating agent. J. Chromatogr. A 2004, 1048, 253-256. [CrossRef]

27. Liang, C.; Yuan, C.Y.; Warmack, R.J.; Barnes, C.E.; Dai, S. Ionic liquids: A new class of sensing materials for detection of organic vapors based on the use of a quartz crystal microbalance. Anal. Chem. 2002, 74, 2172-2176. [CrossRef] [PubMed]

28. Silvester, D.S. Recent advances in the use of ionic liquids for electrochemical sensing. Analyst 2011, 136, 4871-4882. [CrossRef] [PubMed]

29. Jin, X.; Yu, L.; Garcia, D.; Ren, R.X.; Zeng, X. Ionic liquid high-temperature gas sensor array. Anal. Chem. 2006, 78, 6980-6989. [CrossRef] [PubMed]

30. Buzzeo, M.C.; Hardacre, C.; Compton, R.G. Use of room temperature ionic liquids in gas sensor design. Anal. Chem. 2004, 76, 4583-4588. [CrossRef] [PubMed] 
31. Shvedene, N.V.; Chernyshov, D.V.; Khrenova, M.G.; Formanovsky, A.A.; Baulin, V.E.; Pletnev, I.V. Ionic liquids plasticize and bring ion-sensing ability to polymer membranes of selective electrodes. Electroanalysis 2006, 18, 1416-1421. [CrossRef]

32. Zhang, C.; Malhotra, S.V. Increased paraoxon detection by acetylcholinesterase inactivation with ionic liquid additives. Talanta 2005, 67, 560-565. [CrossRef] [PubMed]

33. Wolfbeis, O.S.; Kovacs, B.; Goswami, K.; Klainer, S.M. Fiber-optic fluorescence carbon dioxide sensor for environmental monitoring. Microchim. Acta. 1998, 129, 181-188. [CrossRef]

34. Cooney, C.G.; Towe, B.C.; Eyster, C.R. Optical pH, oxygen and carbon dioxide monitoring using a microdialysis approach. Sens. Actuators B 2000, 69, 183-188. [CrossRef]

35. Tabacco, M.B.; Uttamlal, M.; McAllister, M.; Walt, D.R. An Autonomous Sensor and Telemetry System for Low-Level $\mathrm{pCO}_{2}$ Measurements in Seawater. Anal. Chem. 1999, 71, 154-161. [CrossRef] [PubMed]

36. Ge, X.; Kostov, Y.; Rao, G. Low-cost noninvasive optical $\mathrm{CO}_{2}$ sensing system for fermentation and cell culture. Biotechnol. Bioeng. 2005, 89, 329-334. [CrossRef] [PubMed]

37. Kirk-Othmer Encyclopedia of Chemical Technology. Available online: http://onlinelibrary.wiley.com/ book/10.1002/0471238961 (accessed on 1 December 2015).

38. Encyclopedia of Chemical Technology; Pierantozzi, R., Kroschwitz, J.I., Eds.; Wiley-VCH: New York, NY, USA, 1991.

39. Hapiot, P.; Lagrost, C. Electrochemical Reactivity in Room-Temperature Ionic Liquids. Chem. Rev. 2008, 108, 2238-2264. [CrossRef] [PubMed]

40. Buzzeo, M.C.; Evans, R.G.; Compton, R.G. Non-haloaluminate room-temperature ionic liquids in electrochemistry-a review. Chemphyschem 2004, 5, 1106-1120. [CrossRef] [PubMed]

41. Fuller, J.; Carlin, R.T.; Osteryoung, R.A. The room temperature ionic liquid 1-ethyl-3-methylimidazolium tetrafluoroborate: Electrochemical couples and physical properties. J. Electrochem. Soc. 1997, 144, 3881-3886. [CrossRef]

42. Quinn, B.M.; Ding, Z.; Moulton, R.; Bard, A.J. Novel electrochemical studies of ionic liquids. Langmuir 2002, 18, 1734-1742. [CrossRef]

43. Bates, E.D.; Mayton, R.D.; Ntai, I.; Davis, J.H. $\mathrm{CO}_{2}$ capture by a task specific ionic liquid. J. Am. Chem. Soc. 2002, 124, 926-927. [CrossRef] [PubMed]

44. Oter, O.; Ertekin, K.; Topkaya, D.; Alp, S. Emission-based optical carbon dioxide sensing with HPTS in green chemistry reagents: Room-temperature ionic liquids. Anal. Bioanal. Chem. 2006, 386, 1225-1234. [CrossRef] [PubMed]

45. Oter, O.; Ertekin, K.; Topkaya, D.; Alp, S. Room temperature ionic liquids as optical sensor matrix materials for gaseous and dissolved $\mathrm{CO}_{2}$. Sens. Actuators B 2006, 117, 295-301. [CrossRef]

46. Oter, O.; Ertekin, K.; Derinkuyu, S. Ratiometric sensing of $\mathrm{CO}_{2}$ in ionic liquid modified ethyl cellulose matrix. Talanta 2008, 76, 557-563. [CrossRef] [PubMed]

47. Celik, S.; Ertekin, K.; Gundogdu, C.; Erguna, Y.; Alp, S. Dissolved Carbon Dioxide Sensing with Phenyl-Linked Carbazole Oxazolones in Ionic Liquid and Ethyl Cellulose Moieties. Spectro. Lett. 2012, 45, 74-83. [CrossRef]

48. Oter, O.; Gulhan, S.; Kadriye, E. Enhanced $\mathrm{CO}_{2}$ Sensing with Ionic Liquid Modified Electrospun Nanofibers: Effect of Ionic Liquid Type. Sens. Lett. 2013, 11, 1591-1599. [CrossRef]

49. Aydogdu, S.; Ertekin, K.; Suslu, A.; Ozdemir, M.; Celik, E.; Cocen, U. Optical $\mathrm{CO}_{2}$ Sensing with Ionic Liquid Doped Electrospun Nanofibers. J. Fluoresc. 2011, 21, 607-613. [CrossRef] [PubMed]

50. Aydogdu, S.; Ertekin, K.; Gocmenturk, M.; Ergun, Y.; Celik, E. Emission Based Sensing of Subnanomolar Dissolved Carbon Dioxide Exploiting Electrospun Nanofibers. Int. J. Polym. Mat. Polym. Biomat. 2014, 63, 197-206. [CrossRef]

51. Borisov, S.M.; Waldhier, M.C.; Klimant, I.; Wolfbeis, O.S. Optical Carbon Dioxide Sensors Based on Silicone-Encapsulated Room-Temperature Ionic Liquids. Chem. Mater. 2007, 19, 6187-6194. [CrossRef]

52. Liu, Y.; Tang, Y.; Barashkov, N.N.; Irgibaeva, I.S.; Lam, J.W.Y.; Hu, R.; Birimzhanova, D.; Yu, Y.; Tang, B.Z. Fluorescent Chemosensor for Detection and Quantititation of carbond dioxide gas. J. Am. Chem. Soc. 2010, 132, 13951-13953. [CrossRef] [PubMed]

53. Pandey, S.; Baker, S.N.; Pandey, S.; Baker, G.A. Optically responsive switchable ionic liquid for internally-referenced fluorescence monitoring and visual determination of carbon dioxide. Chem. Commun. 2012, 48, 7043-7045. [CrossRef] [PubMed] 
54. Tian, T.; Chen, X.; Li, H.; Wang, Y.; Guo, L.; Jiang, L. Amidine-based fluorescent chemosensor with high applicability for detection of $\mathrm{CO}_{2}$ : A facile way to "see" $\mathrm{CO}_{2}$. Analyst 2013, 138, 991-994. [CrossRef] [PubMed]

55. Guo, Z.; Song, N.R.; Moon, J.H.; Kim, M.; Jun, E.J.; Choi, J.; Lee, J.Y.; Bielawski, C.W.; Sessler, J.L.; Yoon, J. A Benzobisimidazolium-Based Fluorescent and Colorimetric Chemosensor for $\mathrm{CO}_{2}$. J. Am. Chem. Soc. 2012, 134, 17846-17849. [CrossRef] [PubMed]

56. Xu, Q.; Lee, S.; Cho, Y.; Kim, M.H.; Bouffard, J.; Yoon, J. Polydiacetylene-Based Colorimetric and Fluorescent Chemosensor for the Detection of Carbon Dioxide. J. Am. Chem. Soc. 2013, 135, 17751-17754. [CrossRef] [PubMed]

57. Ishizu, K.; Kan, T.; Takei, Y.; Takahashi, H.; Matsumoto, K.; Shimoyama, I. Carbon dioxide detection by surface Plasmon resonance with ionic liquid. In Proceedings of the IEEE 25th International Conference on Micro Electro Mechanical Systems, Paris, France, 29 January-2 February 2012.

58. Wei, D.; Ivaska, A. Applications of ionic liquids in electrochemical sensors. Anal. Chimi. Acta. 2008, 607, 126-135. [CrossRef] [PubMed]

59. Shiddiky, M.J.A.; Torriero, A.A.J. Application of ionic liquids in electrochemical sensing systems. Biosens. Bioelectron. 2011, 26, 1775-1787. [CrossRef] [PubMed]

60. Barrosse-Antle, L.E.; Compton, R.G. Reduction of carbon dioxide in 1-butyl-3-methylimidazolium acetate. Chem. Commun. 2009, 25, 3744-3746. [CrossRef] [PubMed]

61. Buzzeo, M.C.; Klymenko, O.V.; Wadhawan, J.D.; Hardacre, C.; Seddon, K.R.; Compton, R.G. Kinetic Analysis of the Reaction between Electrogenerated Superoxide and Carbon Dioxide in the Room Temperature Ionic Liquids 1-Ethyl-3-methylimidazolium Bis(trifluoromethylsulfonyl)imide and Hexyltriethylammonium Bis(trifluoromethylsulfonyl)imide. J. Phys. Chem. B 2004, 108, 3947-3954. [CrossRef]

62. Ishizu, K.; Takei, Y.; Honda, M.; Noda, K.; Inaba, A.; Itoh, T.; Maeda, R.; Matsumoto, K.; Shimoyama, I. Carbon dioxide gas sensor with ionic gel. In Proceedings of the 2013 Transducers \& Eurosensors XXVII: The 17th International Conference on Solid-State Sensors, Actuators and Microsystems, Barcelona, Spain, 16-20 June 2013.

63. Honda, M.; Takei, Y.; Ishizu, K.; Imamoto, H.; Itoh, T.; Maeda, R.; Matsumoto, K.; Shimoyama, I. Low-power-consumption $\mathrm{CO}_{2}$ gas sensor using ionic liquids for Green energy management. In Proceedings of the 2012 IEEE Sensors, Taipei, Taiwan, 28-31 October 2012.

64. Xiao, C.; Zeng, X. In Situ EQCM Evaluation of the Reaction between Carbon Dioxide and Electrogenerated Superoxide in Ionic Liquids. J. Electrochem. Soc. 2013, 160, H749-H756. [CrossRef]

65. Rosen, B.A.; Salehi-Khojin, A.; Masel, R.I. A microfabricated carbon dioxide sensor for portable applications. In Proceedings of the 2010 IEEE Sensors, Kona, HI, USA, 1-4 November 2010.

66. Kiga, N.; Takei, Y.; Inaba, A.; Takahashi, H.; Matsumoto, K.; Shimoyama, I. CNT-FET Gas Sensor using a functionalized ionic liquid as gate. In Proceedings of the 2012 IEEE 25th International Conference on Micro Electro Mechanical Systems, Paris, France, 29 January-2 February 2012.

67. Inaba, A.; Yoo, G.; Takei, Y.; Matsumoto, K.; Shimoyama, I. Graphene FET gas sensor gated by ionic liquid. In Proceedings of the 2013 IEEE 26th International Conference on Micro Electro Mechanical Systems, Taipei, Taiwan, 20-24 January 2013.

68. Li, Y.; Li, G.; Wang, X.; Zhu, Z.; Ma, H.; Zhang, T.; Jin, J. Poly(ionic liquid)-wrapped single-walled carbon nanotubes for sub-ppb detection of $\mathrm{CO}_{2}$. Chem. Commun. 2012, 48, 8222-8224. [CrossRef] [PubMed]

69. Willa, C.; Yuan, J.; Niederberger, M.; Koziej, D. When Nanoparticles Meet Poly(Ionic Liquid)s: Chemoresistive $\mathrm{CO}_{2}$ Sensing at Room Temperature. Adv. Functn. Mater. 2015, 25, 2537-2542. [CrossRef]

70. Chen, L.; Huang, D.; Ren, S.; Chi, Y.; Chen, G. Carbon Dioxide Gas Sensor Based on Ionic Liquid-Induced Electrochemiluminescence. Anal. Chem. 2011, 83, 6862-6867. [CrossRef] [PubMed]

71. Sayari, A.; Belmabkhout, Y. Stabilization of Amine-Containing $\mathrm{CO}_{2}$ Adsorbents: Dramatic Effect of Water Vapor. J. Am. Chem. Soc. 2010, 132, 6312-6314. [CrossRef] [PubMed]

72. Yamada, T.; Lukac, P.J.; George, M.; Weiss, R.G. Reversible, Room-Temperature Ionic Liquids. Amidinium Carbamates Derived from Amidines and Aliphatic Primary Amines with Carbon Dioxide. Chem. Mater. 2007, 19, 967-973. [CrossRef]

73. Boydston, A.J.; Williams, K.A.; Bielawski, C.W. A Modular Approach to Main-Chain Organometallic Polymers. J. Am. Chem. Soc. 2005, 127, 12496-12497. [CrossRef] [PubMed] 
74. Tennyson, A.G.; Kamplain, J.W.; Bielawski, C.W. Oxidation of poly(enetetramine)s: A new strategy for the synthesis of conjugated polyelectrolytes. Chem. Commun. 2009, 16, 2124-2126. [CrossRef] [PubMed]

75. Boydston, A.J.; Pecinovsky, C.S.; Chao, S.T.; Bielawski, C.W. Phase-Tunable Fluorophores Based upon Benzobis(imidazolium) Salts. J. Am. Chem. Soc. 2007, 129, 14550-14551. [CrossRef] [PubMed]

76. Holbrey, J.D.; Reichert, M.; Tkatchenko, I.; Bouajila, E.; Walter, O.; Tommasi, I.; Rogers, R.D. 1,3-Dimethylimidazolium-2-carboxylate: The unexpected synthesis of anionic liquid precursor and carbene- $\mathrm{CO}_{2}$ adduct. Chem. Commun. 2003, 28-29. [CrossRef]

77. Duong, H.A.; Tekavec, T.N.; Arif, A.M.; Louie, J. Reversible carboxylation of N-heterocyclic carbenes. Chem. Commun. 2004, 112-113. [CrossRef] [PubMed]

78. Chen, X.; Zhou, G.; Peng, X.; Yoon, J. Biosensors and chemosensors based on the optical responses of polydiacetylenes. Chem. Soc. Rev. 2012, 41, 4610-4630. [CrossRef] [PubMed]

79. Homola, J.; Yee, S.S.; Gauglitz, G. Surface plasmon resonance sensors: Review. Sens. Actuators B 1999, 54, 3-15. [CrossRef]

80. Rosen, B.A.; Haan, J.L.; Mukherjee, P.; Braunschweig, B.; Zhu, W.; Salehi-Khojin, A.; Dlott, D.D.; Masel, R.I. In Situ Spectroscopic Examination of a Low Overpotential Pathway for Carbon Dioxide Conversion to Carbon Monoxide. J. Phys. Chem. C 2012, 116, 15307-15312. [CrossRef]

81. Rosen, B.A.; Salehi-Khojin, A.; Thorson, M.R.; Zhu, W.; Whipple, D.T.; Kenis, P.J.A.; Masel, R.I. Ionic liquid-mediated selective conversion of $\mathrm{CO}_{2}$ to $\mathrm{CO}$ at Low Overpotentials. Science 2011, 334, 643-644. [CrossRef] [PubMed]

82. Richter, M.M. Electrochemiluminescence (ECL). Chem. Rev. 2004, 104, 3003-3036. [CrossRef] [PubMed]

83. Miao, W.J. Electrogenerated chemiluminescence and its biorelated applications. Chem. Rev. 2008, 108, 2506-2553. [CrossRef] [PubMed]

(C) 2015 by the authors; licensee MDPI, Basel, Switzerland. This article is an open access article distributed under the terms and conditions of the Creative Commons by Attribution (CC-BY) license (http:/ / creativecommons.org/licenses/by/4.0/). 